Endocrinol. Japon. 1968, 15 (2), 145 169

\title{
FUNCTIONAL SIGNIFICANCE OF THE TUBULAR AGRANULAR ENDOPLASMIC RETICULUM IN THE ADRENOCORTICAL CELLS OF ALBINO RATS
}

\author{
Fujio YOSHIMURA, Kanji HARUMIYA, Mitsutoshi WATANABE, \\ TSUGUO OMOTO AND TAKAKO SEKIGUCHI
}

Department of Anatomy, Jikei University School of Medicine, Tokyo

\begin{abstract}
SYNOPSIS
An electron microscopical observation was made on the adrenal cortex of rats under hyper- and hypofunctional experiments. Such stimulative factors as administration of $\mathrm{ACTH}$, unilateral adrenalectomy and injection of snake toxin were noted to commonly dilate the anastomosing tubules of the agranular endoplasmic reticula (ER) in the fasciculata cells throughout their length. Furthermore these factors diminished quickly the number of fat droplets. On the other hand, prevention of the pituitary ACTH release due to hypophysectomy induced retrogression of the tubular ER, storage of the fat droplet and destruction of the mitochondria in the atrophic fasciculata cells. The

osmiophilic substance was deposited initially in the confluences of anastomosing tubular ER and grew thereafter into the fat droplet. The probable reason for the rapid loss of fat droplets from the stimulated cells is that the content of fat droplets is transported through the tubular ER. However, in deficiency of the circulating ACTH, fat droplets were stabilized without movement on account of atrophy of the ER. In fact, they increased in number and in size. Elevated ACTH levels resulted in an approximation of the ER to the mitochondria, and the limiting membrane of ER was often adhesive to the external membrane of mitochondria. This topographic connection is favourable to our views that biosynthesis of steroid hormones would be carried out in the lumen of the anastomosing canalicular ER in participation with the enzymes laden on the membranes of mitochondria and ER. The final product of these duct systems seemed to be discharged into the intercellular space, because there was evidence that the terminals of the tubular ER opened into the intercellular space under hyperfunctional conditions.
\end{abstract}

In general the cytoplasm of the cells secreting steroid hormone is rich in vesicular agranular endoplasmic reticula, although the vesicular reticulum has been suspected to be an artifact of fixation (Christensen, 1965). It has so far been thought that these agranular reticula are not separated independently but that they are a part of the continuous mem-

Received for publication December, 3, 1967. brane system, forming the anastomosing canaliculus. For example, in the interstitial cells of the testis the anastomosing tubular reticulum has been verified (Christensen and Fawcett, 1961; Crabo, 1963; Christensen, 1965). Also in the ovarian lutein cel's, cevelopment of the interconnecting tubulcs of agranular endoplasmic reticula was found (Enders 1962; Enders and Lyons, 1964). On the other hand, a network of tubula ${ }_{-}$endo- 
plasmic reticula in the adrenocortical cells has not been verified fully. Only Ross et al. (1958) observed interconnecting tubules without local dilatation in the adrenocortical cells of human embryos, and Brenner (1966) found the tubules in the fasciculata cells of the adrenal glands of monkeys. Recently Yonetsu (1966) demonstrated the networking canalicular endoplasmic reticula in the cortical cells of hamsters.

A fine network of tubular agranular endoplasmic reticula engorging many vesicles like the beads of a rosary has been observed in the present electron microscopic observation on the adrenocortical cells in normal and experimental rats. In a series of experiments concerning the hyper- and hypofunctional status of the adrenal cortex, changes of the organelles in the cortical cells, especially alterations in the form and disposition of the tubular granular endoplasmic reticula were examined. The purpose of this electron microscopic study was to gain some understanding concerning the role of the canalicular system in steroid hormone biosynthesis in the cortical cells.

\section{MATERIALS AND METHODS}

All animals used in this study were male Wistar-Imamichi rats, litter mates, 90 to 100 days of age. They were kept at constant room temperature $\left(25^{\circ} \mathrm{C}\right)$ and fed a $\mathrm{CE}$ diet (Central Lab. of Experimental Animals in Tokyo) to which was added some kinds of vegetable. They were divided into 6 groups. Group 1, the normal intact controls, consisted of 7 rats. Group 2, non-operated ten rats, receiving a single subcutaneous injection of $10 \mathrm{mg}$ or $25 \mathrm{mg}$ of adrenocorticotrophin (Organon) per rat and they were sacrificed 30 mins. after injection. Group 3, unilaterally adrenalectomized rats, sacrificed at $1,3,7,14$ and 30 days after operation; the number of animals in each time-interval group after the operation was six. Group 4, 18 intact rats, administered subcutaneously $200 \mathrm{mg} / \mathrm{kg}$ of the snake toxin powder (Trimeresurus flavoviridis) prepared at the Institute of Medical Science,
Tokyo University and sacrificed at 30 mins., 1, 3 and 6 hrs. after the injection. Group 5, 12 rats hypophysectomized via auditory route (Koyama, 1962) and sacrificed at 12 and 65 hrs., 7 and 18 days after the operation; the number of animals in each time-interval group was three. Group 6, hypophysectomized rats, receiving a single subcutaneous dose of adrenocorticotrophin 5 I.U. (Organon), 12, 65 hrs., 7 and 18 days after the operation respectively; the number of animals in each time-interval group was three or four, and the animals were sacrificed at 30 mins. after the injection.

For electron microscopy, small pieces of tissue of the adrenal gland were fixed in $2 \%$ osmium tetroxide in $\mathrm{pH} 7.4$ phosphate buffer solution (Millonig, 1961) or in $\mathrm{pH} 7.4$ veronal acetate buffer solution for $2 \mathrm{hrs}$; some of the tissues were fixed, if necessary, in $3 \%$ glutaraldehyde phosphate buffer of $\mathrm{pH}$ 7.4. Following fixation, the tissues were dehydrated in increasing percentage of cold ethanol, treated wiht propylenoxyde for 10 mins., infiltrated and embedded with Luft's epon resin 812 . Thin sections were made with a Porter-Blum ultratome, mounted on copper grids, and stained with lead hydroxide (Reynalds, 1963). The sections were examined with a J. E. O. L. 7-A electron microscope.

\section{OBSERVATIONS}

The fine structure of the adrenal cortex in the normal control rats was described in our preceding paper entitled "The light and electron microscopic studies on the zonation of the adrenal cortex in the rat." Reference to this paper (Yoshimura et al., 1968) will aid in the understanding of the present results.

\section{Changes in the fasciculata cells of rats ad- ministered corticotrophin}

Thirty mins. after a single subcutaneous injection of corticotrophin $(10 \mathrm{mg}$ of ACTH per rat), the fasciculata cells underwent a marked change. The cell-strands of the zona fasciculata elongated toward the capsule, and the zona glomerulosa showed a fascicular 
appearance simulating upperward invasion of the zona fasciculata. The formation of the typical glomerulum scarcely took place in the superficial region of the cortex. Most of the fasciulata cells were very rich in spherical mitochondria with vesicles. At the same time fat droplets dispersed quickly (Fig. 1). Thus, a rapid increase of the mitochondrial population and a rapid loss of fat droplets were the major acute changes in the cells of the zona fasciulate following the administration of $10 \mathrm{mg}$ of ACTH. On the other hand, the agranular endoplasmic reticula (ER) were not affected remarkably by this dosage of $\mathrm{ACTH}$, and vesiculation of ER was not evident. There was no reliable evidence of the interdigitation of the microvilli in the intercellular space.

When a larger dose of ACTH was given (25mg per rat), the above-mentioned alterations in the organelles became more profound. In particular, the occurrence of numerous enlarged vesicles in the cytoplasm was noted, and this fact accounted for the uniform dilatation of the tubular ER. These vesicles reached $0.1-0.2 \mu$ in diameter. The expanded vesicles were frequently in contact with the outer membrane of the mitochondria (arrow in Fig. 2). Development and distribution of the Golgi lamellae were not markedly influenced by the injection of ACTH. The number of free ribosomes was also unchanged, while lysosomal bodies showed a tendency to diminish in number. The reticularis cells seemed to be stimulated to some degree by the ACTH administration, because the submicroscopic structure of the cells was identical with that of the stimulated fasciculata cells.

\section{Changes in the fasciculata cells of unilaterally adrenalectomized rats}

The adrenal weight increased gradually after unilateral adrenalectomy. The glomerulum in the zona glomerulosa was sooner or later involuted following unilateral adrenalectomy. On the following day of operation, the glomerulum was modified in shape and elongated to be perpendicularly arranged in a row. This prompt modification was also observed easily by light microscopy. The cellstrands descending from the capsule were transformed into the underlying fasciculata without intervention of the transitional zone. On the other hand, small glomeruli remained under the capsule.

The prelude to cytological changes in the fasciculata cells began with a rapid loss of fat droplets. Even on the next day of operation, most fat droplets vanished due to unknown mechanism, but the degree of change in the tubular ER was different from cell to cell. In some cells the tubular ER were slightly dilated, while in others they were changed into slender canaliculi which were bound up closely with the mitochondria (Fig. 6). A noticeable subcellular change took place in the mitochondria: the multiplied mitochondria often had protuberances on their surface, which were surrounded by a number of laminifications.

On the third day of unilateral adrenalectomy, the whole zona glomerulosa was occupied by elongated cell-strands resembling the zona fasciculata. This development corresponds with the change of the cells in rats administered ACTH. The typical fascicular arrangement of the cortical cells occurs apparantly from persistent secretion of ACTH from the hypophysis. The fasciculata cells were noted to have fine structural changes such as marked dilatation of ER and the disappearance of droplets. The tubular ER may swell throughout its length, since the hyaloplasm is full of large vesicles which may be produced by cross-sectioning of the dilated tubular ER (Fig. 3). The maximal diameter of ER reached $0.3 \sim 0.4 \mu$. The microvilli were interdigitated in the intercellular space more densely. It is noteworthy that the vesicles not only approximate to the mitochondria but also attach to their outer membrane. It was often successfully demonstrated that the limiting membrane of vesicles was adhesive to the outer membrane of the mitochondria (arrow in Fig. 7). Cross-sections of the protuberances of the mitochondria surrounded by 
multilaminifications looked often vesicles and their center became sometimes high in electron density. Their cross-sections looked also like isolated, encircled bodies (arrow in Fig. 3). On the 7th day of operation, the changes did not advance beyond the level on the third day. A slight decrease in dilatation of the tubular ER was perceptible: the large vesicles decreased in number and reverted to their normal size. On the 14th day of operation, the lumen of the enlarged vesicles were closed. Aggravated peristaltic movement passing along the tubular ER which consists of a wave of dilation returned to normal in accordance with normalization of the size and frequency of the vesicles. Within 30 days, submicroscopical changes were responsible for chronic response. The tubular ER were rather reduced in diameter, and the hyaloplasm of the cells was penetrated by slender canaliculi without dilatation (Fig. 4). These canaliculi attached to the mitochondria and surrounded them, showing a fine meshwork among the mitochondria. The canaliculi frequently entered the peripheral homogeneous zone of the cells and eventually approximate to the intercellular space (arrow in Fig. 4). It appeared that the fine structure of the fasciculata cells varied with the lapse of postoperative time: it was postulated that the tubular ER were closed immediately after operation, and it dilated extremely in the acute phase, dilated moderately in the subacute phase and finally were closed again in the chronic phase. Multiplication of the mitochondria and loss of fat droplets were common phenomena throughout the entire phase.

\section{Changes in the cortical cells of rats provoked by snake toxin}

Within 30 mins. after the administration of the snake toxin, certain cytological changes were observed in the zona glomerulosa. These were followed by a fascicular arrangement of the zona glomerulosa after $2 \sim 6 \mathrm{hrs}$. This cellular arrangement corresponded with that seen in the rats unilaterally adrenalectomized or administered ACTH. There were fine structural evidences that the fasciculata cells were stimulated. The first sign of hyperactivity was a rapid loss of fat droplets. The second sign which appeared within 30 mins. was a network formation of the slender canalicular ER (Fig. 5). These canaliculi often surrounded the mitochondria, or they were sometimes adhesive to the outer membrane of mitochondria which increased in number in the initial phase of stress. This canaliculus may be identical in nature with that seen in an early phase after unilateral adrenalectomy (30 mins.). Also a temporal decrease in free ribosomes might be a reflexion of an abnormal stress upon the cortical cells, because within 1 to $6 \mathrm{hrs}$. the free ribosomes reappeared. The enlarged vesicles accumulated in the cytoplasm (Fig. 8), which were nothing but the product of cross-sectioning of the excessively expanding tubular ER. Small osmiophilic fat droplets were still left intermingled with the vesicles (Fig. 8). Thus, the first acute influence of the stress exerted upon the cortical cells by the snake toxin was a tremendous expansion of the canalicular ER. This observation is in agreement with that of Harumiya (1966) that the intercellular space with the numerous microvilli is full of the particular dense granules of $200 \mathrm{~m} \mu$ in diameter 2 hrs. after an injection of snake toxin.

\section{Changes in the cortical cells of hypophysectomized rats}

It has been well established that hypophysectomy induces a marked atrophy of the zona fasciculata within 7 to 10 days. In accordance with our previous observation (Yoshimura, 1954; Yokosuka, 1960), the zona glomerulosa and zona intermedia increased in width and showed an appearance of fascicular arrangement as a sequence of the compensatory response to a marked reduction in size of the zona fasciculata, noted in 10 days after hypophysectomy.

Within 12 hrs. after hypophysectomy, the fasciculata cells were profoundly degenerated without much change in the glomerulosa cells. 
The effect of hypophysectomy upon the fasciculata cells was so serious that morphological evidence of change was easily seen by electron microscopy: the predominant alterations were deformation or destruction of the mitochondria and loss of the tubular ER. Figure 9 shows the irregular mitochondria of variable size in the fasciculata cells. The regional limiting membrane of many mitochondria is not greatly affected by ACTH deficiency but sometimes yields to it and disappear. The mitochondrial matrix including vesicles was, thereby, diffused into the hyaloplasm (Fig. 9). The mitochondria sometimes bulged to form protuberances or often elongated into a crooked form. These protuberances are surrounded by multilaminifications similar to those already described by us in the unilaterally adrenalectomized rats. It was difficult to distinguish the destroyed mitochondria from the hyaloplasm where many canalicular ER were concentrated. The cytoplasm looked amorphous on account of poor development of the tubular ER, whereas the free ribosomes did not decrease in number. However, fat droplets were not increased.

Degeneration, damage and collapse are suggested as chronic signs of hypophysectomy in the fasciculata cells. Within 65 hrs. deformation of the mitochondria and destruction of the tubular ER became more serious in some cells (Fig. 11). The presence of dense inclusion bodies may be involved in the deepest cell-exhaustion. A collapsed cell packed with mitochondria and fat droplets was observed. On the other hand, numerous normal cells were seen among the degenerating cells. The population ratio of both cells is different from animal to animal.

In seven and eighteen days after hypophysectomy, the boundaries among the cells of the wide zona glomerulosa became extremely complicated (Fig. 18). Fat droplets in the zona glomerulosa excluding its deepest region continuous to the zona intermedia were usu- ally small both in size and number, whereas the glomerulosa cells included numerous round and irregularly shaped mitochondria having the canalicular cristae (Fig. 18). The glomerulosa cells were characterized by a high incidence of large vesicles and also by a well-developed Golgi apparatus ( $\mathrm{G}$ in Fig. 18), which may account for the production of secretory materials.

The contour of the glomerulosa cells became more simple in the vicinity of the transitional zone (Fig. 15). The deeper glomerulosa cells surrounded by the stretched cytomembrane contained many fat droplets deposited in the complicated sacks (Fig. 15). Thin processes of the sacks might be seen communicating with the tubular ER. Most mitochondria in the deeper glomerulosa cells kept a spherical shape but sometimes included a pseudocrystaline array, and canaliculization and subsequent vesiculation of the mitochondrial crista did not appear.

The proliferated transitional zone was, in general, composed of the small flat or ellipsoid particular cells rich in mitochondria of round and irregular shape (Fig. 14). The cells of the transitional zone were not always devoid of fat droplets, but they contained fat droplets of small size and lysosomal bodies (Fig. 14). The ground matrix of cytoplasm was penetrated by the anastomosing and expanded canalicular ER, because there were many large vesicles scattered among the mitochondria.

Within 7 and 18 days after hypophysectomy, degeneration of the fasciculata cells was most severe in degree and resulted in sedimentation of numerous big fat droplets (at right, Fig. 14). The intramitochondrial vesicles tended to spread over to the periphery, displaying a rattan blind* appearance, (arrow in Fig. 17); the center of the mitochondria was low in electron density. Degeneration of the mitochondria terminated in a tremendous reduction in size, and eventually they were absorb-

\footnotetext{
* A kind of Japanese blind, made with slats of rattan, that is hung against an open window to keep out light, and may be closed by rolling it.
} 
ed into the hyaloplasm with disappearance of the limiting membrane (Fig. 17). The tubular ER ended in shrinkage and decreased frequency of appearance. Conversely, the fat droplets were stabilized and appeared to be stocked up voluminously for a long period.

\section{Effect of adrenocorticotrophin upon the} fasciculata cells of the hypophysectomized rats

The effect of ACTH upon the fasciculata cells in the hypophysectomized rats is dependent on the time-interval between hypophysectomy and ACTH injection. Recovery from atrophy or some degenerative signs of the fasciculata cells was attained by the injection of 5 I.U. of ACTH to the hypophysectomized animals, which survivied for 12 and $65 \mathrm{hrs}$. When the interval was more than 7 days, the same dose of ACTH injection did not repair the severe degeneration effectively.

The morphological evidences of the influence by ACTH were as follows: such fine structural signs of hypophysectomy as an accumulation of large fat droplets and degeneration of the mitochondria were dispersed. When the injection of ACTH was begun within the scope of $12 \mathrm{hrs}$, , the structure of the recovered mitochondria including many vesicles were apparently normal, but the incidence of mitochondria in the fasciculata cells seemed to be elevated, because the fasciculata cells contained more numerous mitochondria than those in the normal intact rats (Fig. 10). The poor development of the tubular ER in the hypophysectomized rats was ameliolated quickly by the ACTH therapy, and the incidence of the interconnecting ER became higher (Fig. 10). In figure 10, the dilated tubular ER form a splendid network which is distributed densely in the mitochondria. The maximal development of the anastomosing ER may suggest the highest peak of cellfunction. It is an original picture in the hypophysectomized rat receiving the injection of ACTH that the lumen of the dilated tubular ER was usually of high density.

When the hypophysectomized rats were injected singly with 5 I.U. of ACTH 65 hrs. after the operation, the fasciculata cells recovered adequately from collapse and marked degeneration. Evidence of the hyperfunctional state-multiplication of mitochondria and loss of fat droplets-was present (Fig. 12). Similarly, the tubular ER revealed a fine network, which extended to the periphery of the cytoplasm, and finally came in contact with the cytomembrane facing the intercellular space (arrow in Fig. 13). The possibility was thus noted that the canalicular ER opened into the intercellular space (arrow in Figs. 19 and 20).

When the hypophysectomized animals were injected with ACTH after time-intervals of 7 and 18 days, the profoundly degenerative changes could not be corrected at all. Accumulation of fat droplets, destruction of the mitochondria and reduction of the tubular ER in number and in size, were sustained in the fasciculata cells without any improvement (Fig. 16). When the replacement therapy of ACTH was delayed more than 65 hrs., it was no longer capable of restoring the organelles.

\section{DISCUSSION}

Concerning the locus of steroid hormone production in the adrenocortical cells there has been a controversy among electron microscopists. The first opinion deals with the intramitochondrial expanded vesicle which may actually be the agranular ER in the hyaloplasm (Ashworth et al., 1959; Yoshimura, 1961; Schwarz et al., 1962; Sabatini et al., 1962). The second deals with the open mitochondria and disappearance of the mitochondrial membrane, thereby the content of the intramitochondrial vesicles is released into the hyaloplasm (Nishikawa et al., 1963; Giacomelli et al., 1965). The third deals with intramitochondrial fat deposits (Lever, 1955; Luse, 1961, Yamori et al., 1961; Weber et al., 1962; Giacomelli et al., 1965).

The first theory was based on a chronic response of the cortical cells to the prolonged administration of variable amounts of $\mathrm{ACTH}$, 

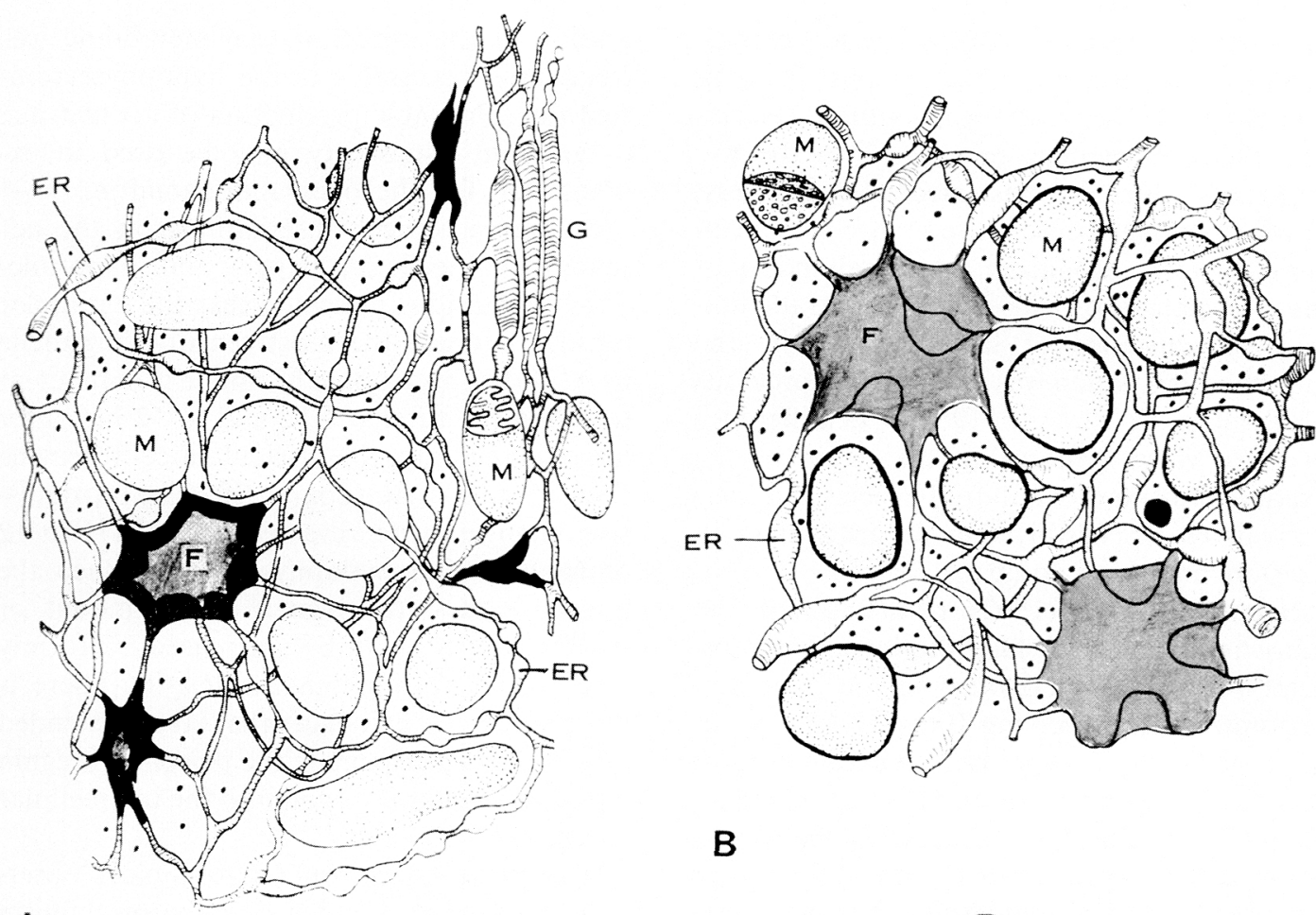

A

\section{B}
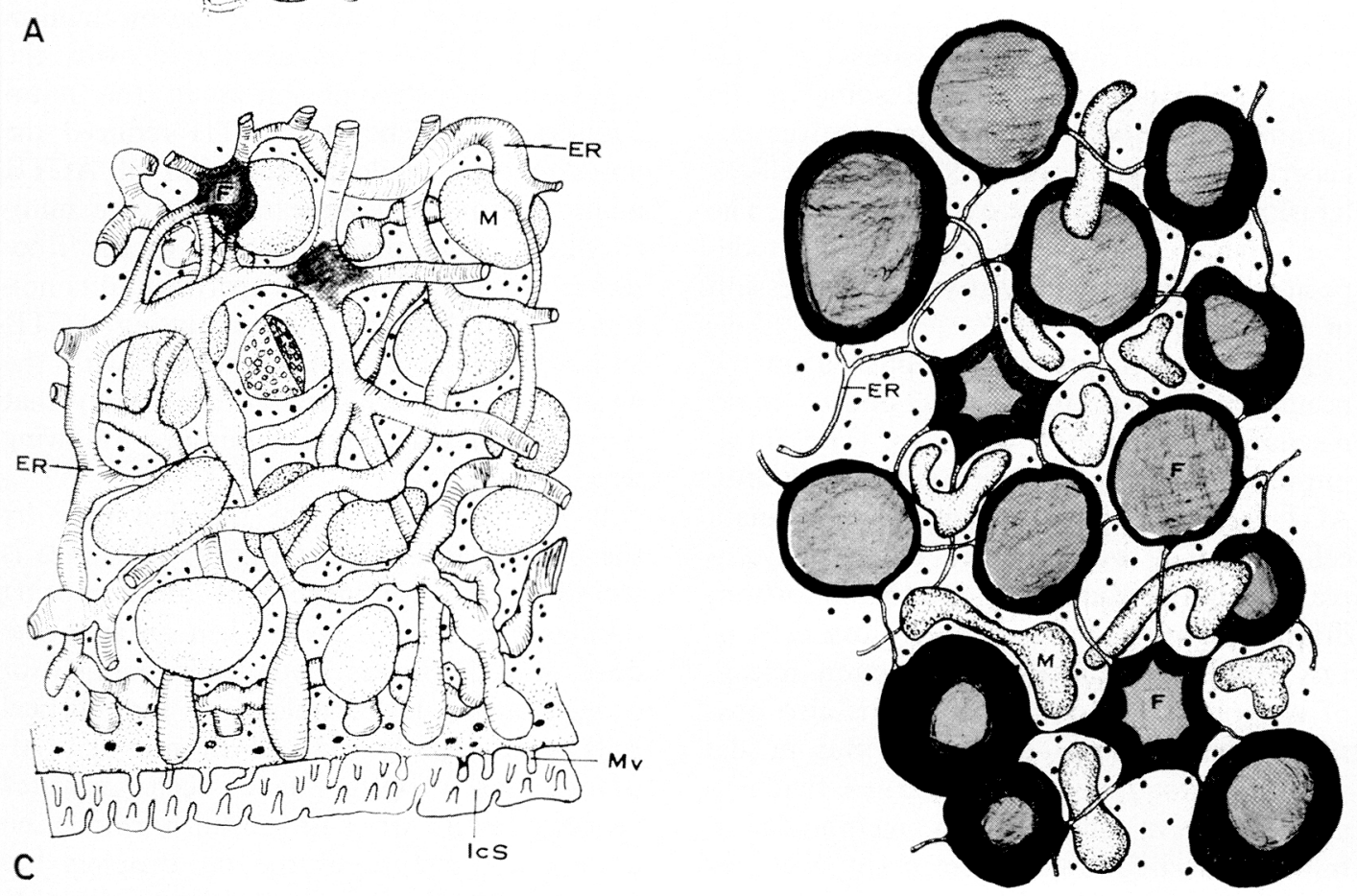

Fig. 21. A diagrammatic representation showing changes of the canalicular ER in the adrenocortical cells under hyper- and hypofunctional status. A, normal glomerulosa cell; B, normal fasciculata cell; C, hyperfunctional fasciculata cell; D, hypofunctional fasciculata cell. M, mitochondria; F, fat droplet; G, Golgi lamellae; ER, endoplasmic reticulum; MV, microvilli; IcS, intercellular space. 
or to long-term effects of unilateral adrenalectomy. The electron micrographs showing dilatation of the intramitochondrial vesicles and their subsequent prolapse into the hyaloplasm were demonstrated. Nevertheless, in the present observation no expanded vesicles were recognized in mitochondria of the stimulated cortical cells, in contradiction to the occurrence of large vesicles in the mitochondria which was noted in our previous observation (Yoshimura 1961). The difference in these views concerning the origin of the expanded intramitochondrial visicles and their derivatives is possibly due to an artifact in fixation and embedding.

Sabatini et al. (1962) demonstrated the mitochondria from which the intramitochondrial vacuoles are extruded in the hypophysectomized rats receiving $10 \mathrm{mg}$ of $\mathrm{ACTH}$ per day for 3 days. However, this observation that tenacious degenerative signs of the mitochondria remained in the cortical cells was equivocal, because repair therapy began after an interval of a month. Yamori et al. (1961) claimed that in rats receiving stress or longterm administration of ACTH some of the intramitochondrial vacuoles simulate the degenerative fat substance peculiar to cell-exhausion due to persistent overstimulation. The third theory-the intramitochondrial fat deposit-is, therefore, indicative of suppression of cell function.

The second theory was established on the premise that the open mitochondria could discharge hormonal precursors. The intramitochondrial vesicles increased rapidly after ACTH-Z administration in the fasciculata cells and they were released into the hyaloplasm with desquamation of the mitochondrial mem'?rane. In the glomerulosa cells of rats with long-term sodium restriction, release of the intramitochondrial vesicle is also possible (Giacomelli et al., 1965). But in the present investigation it was learned that disappearance of the limiting membrane of mitochondria followed more easily the prolonged hypofunctional condition than the hyperfunctional one. For example, disinte- gration of the mitochondrial membrane was frequently discernible in the hypophysectomized rats. Probable production of artifact due to an unfit osmolarity may be used in explantation for the open mitochondria.

Submicroscopical observations on the adrenocortical cells in hyper- and hypofunctional conditions indicated that the agranular tubular ER was the most sensitive organelle to ACTH. This trophic hormone is competent to retain the tubular ER, and in $12 \mathrm{hrs}$. after hypophysectomy, the fasciculata cells became poor in the slender tubular ER. The retrogressive changes were reversed by ACTH in 12 or 68 hrs. after hypophysectomy. When the normal rats were given a large amount of $\mathrm{ACTH}$, the tubular ER increased uniformly in diameter throughout the length. There is morphological evidence that the distended tubular ER approximate the peripheral region of the cells and may open into the intercellular space.

The present electron microscopical observations support the idea that the mechanism of ACTH function is associated with the regulation of steroidogenesis in the mitochondria. Deficiency of ACTH reduced the mitochondria, while an injection of ACTH made a prominent appearance of the mitochondria. Quantitative change of the ribosomes did not follow the experimental conditions which lowered the circulating ACTH level. This fact is not in accord with the observation of Schwarz et al. (1962) that the ribosomes decrease in number following hypophysectomy.

It has been shown for the first time by the present authors that the fat substance is stored in the confluences of anastomosing tubular ER (Fig. 21, A). When an adequate dose of ACTH was given endogenously or exogeneously, fat droplets in the cortical cells were rapidly reduced in number. Although fat droplets have been regarded generally as a carrier of steroid hormone, no discharging picture of the fat droplets has ever been confirmed. From the present observation the following speculation is tenable: 
the content of fat droplets, which may consist of cholesterol and other substances, could be transfered through the uniformly swollen luminal pathway of the interconnecting tubular ER to the peripheral region of the cells, and released into the intercellular space (Fig. $21 \mathrm{C})$. Therefore, the network of ER might be available for the transportation of cholesterol and other compounds or precursors of steroid hormone which may stem from the fat drop lets.

There is much information available concerning interrelationships between the mitochondria and steroidogenesis. The biochemical data on this subject suggest the submicroscopic localization of enzymes necessary for steroidogenesis (Hechta and Pincus, 1954; Stone and Hechta, 1954; Saba and Hechta, 1955; Hyano et al., 1956; Beyer and Samuel, 1956; Haynes and Berthet, 1957; Ryan and Engel, 1957; Péron and Koritz, 1960; Lipscomb and Nelson, 1962; Shima and Matsuba, 1963; Ulrich and Slusher, 1964). The present study of electron microscopy has shown that the tubular ER either adhere closely to the mitochondria or surround them. Thus, a strong local affinity of the ER for the mitochondria was observed. The fact that the external membrane of mitochondria lies on the limiting membrane of ER may suggest a high permeability of the single layer of membrane from the ER to the mitochondria or vice versa.

In experiments in which the adrenal glands are perfused with blood containing various substrates, Hechta and Halkerston (1964) found the dilated cisternae of ER by electron microscopy, when a small amount of ACTH was added to the substrates. They assumed that the anastomosing tubular ER in the cortical cells responded to cyclic dilation and contraction alternately. The continuous membrane of the macromolecular solid-phase of ER may be made up of a contractile substance akin to actomyosin. This substance could be responsible for the oscillatory movement. Although Hechta considered that the microsomal fraction includes the organelles indispensable to steroidogenesis, it is impossible to exclude completely the intrusion of fragments of ER from the microsomal fraction. Hechta and Halkerston (1964) suggested that an oscillatory movement of the tubular ER is a mechanical stimulator to provoke steroidogenesis which may take place in the microsomal fraction. However, the present authors conceive that the locus of steroidogenesis may be the lumen of ER, and the free ribosomes may have no direct concern with steroidogenesis. From our electron microscopical observation, it was assumed that the synthesis of active hormones from cholesterol might be performed in the lumen of the anastomosing tubular ER with the aid of specific enzymes attached to the limiting membrane of ER and onto the external membrane of mitochondria.

Destruction of the mitochondria and simultaneous loss of the tubular ER are characteristics of the adrenocortical cells under inhibitory function. Due to retrogressive changes of the ER, the content of fat droplets could not be easily transfered through the lumen of the slender ER and subsequently stored in the cell-body without mobilization over a long period (Fig. 21, D).

Finally, the responses of the zona golmerulosa to administration of ACTH, unilateral adrenalectomy and violent irritation are now discussed. It has been well established that the zona glomerulosa secretes aldosterone in participation with the renin-angiotensin system, while the zona fasciculata produces glucocorticoid under the influence of hypophyseal ACTH. This theory is based on the dualism concept of corticoid secretion of Deane et al. (1948). Nevertheless, biochemical and histological data contradictory to the dualism theory have been accumulated (Jones and Spalding, 1954; Jones and Wright, 1954; Knigge, 1954; Wexler and Rinfret, 1955; Rauschkolb et al., 1956; Giroud et al., 1956; Nagy et al., 1957; Kovács et al., 1957; Llaurado, 1957; Hill et al., 1959; Ayres, 1959; Crabbé et al., 1959; Davis et al., 1960; Kagawa and Jacob, 1960; Voth et al., 1963; 
Tonutti and Bayer ,1964; Miller, 1965). The present authors have observed that the zona glomerulosa and transitional zone are simultaneously liable to be reconstructed into the fascicular arrangement immediately after the onset of cortical stimulation. The acute disappearance of the transitional zone may occur as the result of the reorganization of this zone. The ultrastructure of the glomerulosa cell was not affected in an early phase of the excitement and represented the normal picture in spite of the marked evolution of the cell arrangement. The entire zona glomerulosa came, in a later phase, to be composed of the cell-strands which were synonymous with prolongation of the cords in the zona fasciculata. A small number of the round glomeruli were sometimes left beneath the capsule. These cell-strands in the zona glomerulosa were provided with the subcellular features corresponding with those in the fasciculata cell. This may account for the subsequent reorganization of the zona glomerulosa following the primary enlargement of the zona fasciculata. It was already pointed out in the light microscopic observation by Yoshimura (1954) that such an upward elongation of the cords of the zona fasciculata was attributable to the overproduction of ACTH in rats. In this electron microscopical study, it was suggested that the zonae glomerulosa and fasciculata were not always independent. Propst and Müller (1966) assumed by their electron microscopy that all cells of the cortex of the rat produced uniformly the preliminary phase of the hormones, which were finally transformed into the original steroids by the specific zonal organelles. Our present observation supports the view of Propst and Müller.

\section{REFERENCES}

Ashworth, C. T., G. J. Race and H. H. Mollenhauer (1959). Amer. J. Pathol. 35, 425.

Ayres, P. J. (1959). Biochem. J. 71, 34.

Beyer, K. F. and L. T. Samuel (1956). J. Biol. Chem. 219, 69.
Brenner, M. R. (1966). Amer. J. Anat. 119, 429. Christensen, A. K. (1965). J. Cell Biol. 26, 911.

Christensen, A. K. and D. W. Fawcett (1961). J. Biophys. Biochem. Cytol. 9, 653.

Crabbé J., W. J. Reddy, E. J. Ross and G. W. Thorn (1959). J. Clin. Endocrinol. and Metabolism 19, 1185.

Crabo, B. (1963). Z. Zellforsch. 61, 587.

Davis, J. O., N. A. Yankopoulos, F. Lieberman, J. Holman and R. C. Bahn (1960). J. Clin. Invest. 39, 765.

Deane, H. W., J. H. Shau and R. O. Greep (1948). Endocrinology 43, 133.

Enders, A. C. (1962). J. Cell Biol. 22, 127.

Enders, A. C. and W. R. Lyson (1964). Ibid. 22, 127.

Giacomelli, F., J. Wiener and D. Spiro (1965). Ibid. 26, 499.

Giroud, C. T. P., J. Stackenko and E. H. Venning (1956). Proc. Soc. Exptl. Biol. Med. 92, 154.

Harumiya, K. (1966). Endocrinol. Japon. 13, 200.

Haynes, R. C. and L. Berthet (1957). J. Biol. Chem. 225, 115.

Hechta, O. and G. Pincus (1954). Physiol. Rev. 34, 459 .

Hechta, O. and I. D. K. Halkerston (1964). The Hormone 5 (Academic press), 697.

Hill, M., Dvorák K. and M. Pospísil (1959). Nature 183, 1819.

Hyano, N., M. Saba, R. I. Dorfman and O. Hechta (1956). Recent Progr. in Hormone Research 12, 79.

Jones, Chester, I. and M. H. Spalding (1954). J. Endocrinol. 10, 251.

Jones, Chester, I. and A. Wright (1954). Ibid. 10, 262.

Kagawa, C. M. and R. S. Jacobs, Jr. (1960). Proc. Soc. Exptl. Biol. Med. 104., 60.

Knigge, K. M. (1954). Endocrinology 55, 731.

Kovács, K., B. M. Kovács, G. S. Kovács and G. Petri (1957). Naturwissenschaften 44, 241. Koyama, R. (1962). Endocrinol. Japon. 9, 312. Lever, J. D. (1955). Amer. J. Anat. 97, 409. Lipscomb, H. S. and D. H. Nelson (1962). Endocrinology 71, 13.

Llaurado, J. G. (1957). Metabolism 6, 556.

Luse, S. A. The Adrenal Cortex (edited by $\mathrm{H}$. 
D. Monn) Paul B. Hoeber Inc. p. 46 (1961). Miller, R. A. (1965). Acta Endocrinol. (Kbh) 50, 493.

Millonig, G. (1961). J. Biophys. Biochem. Cytol. Supple. 11, 736.

Nagy, A., A. Olah and S. Karady (1957). Nature 180, 1481.

Nishikawa, M., I. Murone and T. Sato (1963). Endocrinology 72, 197.

Péron, F. C. and S. B. Koritz (1960). J. Biol. Chem. 235, 1625.

Propst, A. and O. Müller (1966). Z. Zellforsch. 75, 404.

Rauschkolb, E. W., L. Gordon, G. L. Larrel and S. Koletsky (1956). Amer. J. Physiol. 184, 55.

Reynalds, E. S. (1963). J. Cell Biol. 17, 208.

Ross, M. H. G. D. Pappas and J. Lind (1958). J. Biophy. Biochem. Cytol. 4, 659.

Ryan, K. J. and L. L. Engel (1957). J. Biol. Chem. 225, 103.

Saba, N. and O. Hechta (1955). J. Biophys. Biochem. Cytol. 9, 105.

Sabatini, D. D., E. D. P. De Robertis and H. B. Bleichmar (1962). Endocrinology 70, 390.

Schwarz, W., H. J. Merker and G. K. Suchowsky (1962). Virchows Arch. 335, 165.
Shima S. and M. Matsuba (1963). J. Physiol. Soc. Japan 25, 337. (In Japanese)

Stone, D. and O. Hechta (1954). Arch. Biochem. Biol. 51, 457.

Tonutti, E. and J. M. Bayer (1964). Europ. Rev. Endocrinol. 1, 201.

Ulrich, R. and M. A. Slusher (1964). Endocrinology 75, 483.

Voth, D., K. Kohlhardt and K. Tietze (1963). Frankfurt Z. Pathol. 72, 428.

Weber, A. F. E., A. Usenik and S. C. Whipp (1962). 5th International Congress for Electron Microscopy. New York Academic press 2.

Wexler, B. C. and A. P. Rinfret (1955). Endocrinology 57, 608.

Yamori, T., S. Matsuura and S. Sakamoto (1961). Z. Zellforsch. 55, 179.

Yokosuka, A. (1960). Acta Endocrinol. Japon. 35, 1498. (In Japanese)

Yonetsu, T. (1966). Endocrinol. Japon. 13, 269.

Yoshimura, F. (1954). Ibid. 1, 177.

Yoshimura, F. (1961). Acta Endocrinol. Japon. 37, 495. (In Japanese)

Yoshimura, F., K. Harumiya, N. Suzuki and S. Totsuka (1968). Endocrinol. Japon. 15, 20. 
Fig. 1. A fasciculata cell from a male rat, 30 mins. after injection of $10 \mathrm{mg}$ of ACTH. A rapid loss of fat droplets (F) takes place in the cell-bodies, and the mitochondria (M) multiply. In an early phase the canalicular ER are neither dilated nor increased in number. $\times 16,000$

Fig. 2. A fasciculata cell from a male rat, 30 mins. after injection of $25 \mathrm{mg}$ of ACTH. A large dose of ACTH elevated the incidence of the expanded canalicular or vacuolar ER. The fat droplets $(F)$ are hardly detectable in the cell-body. Arrow shows a topographic affinity of the ER to the mitochondria (M). $\times 25,000$ 

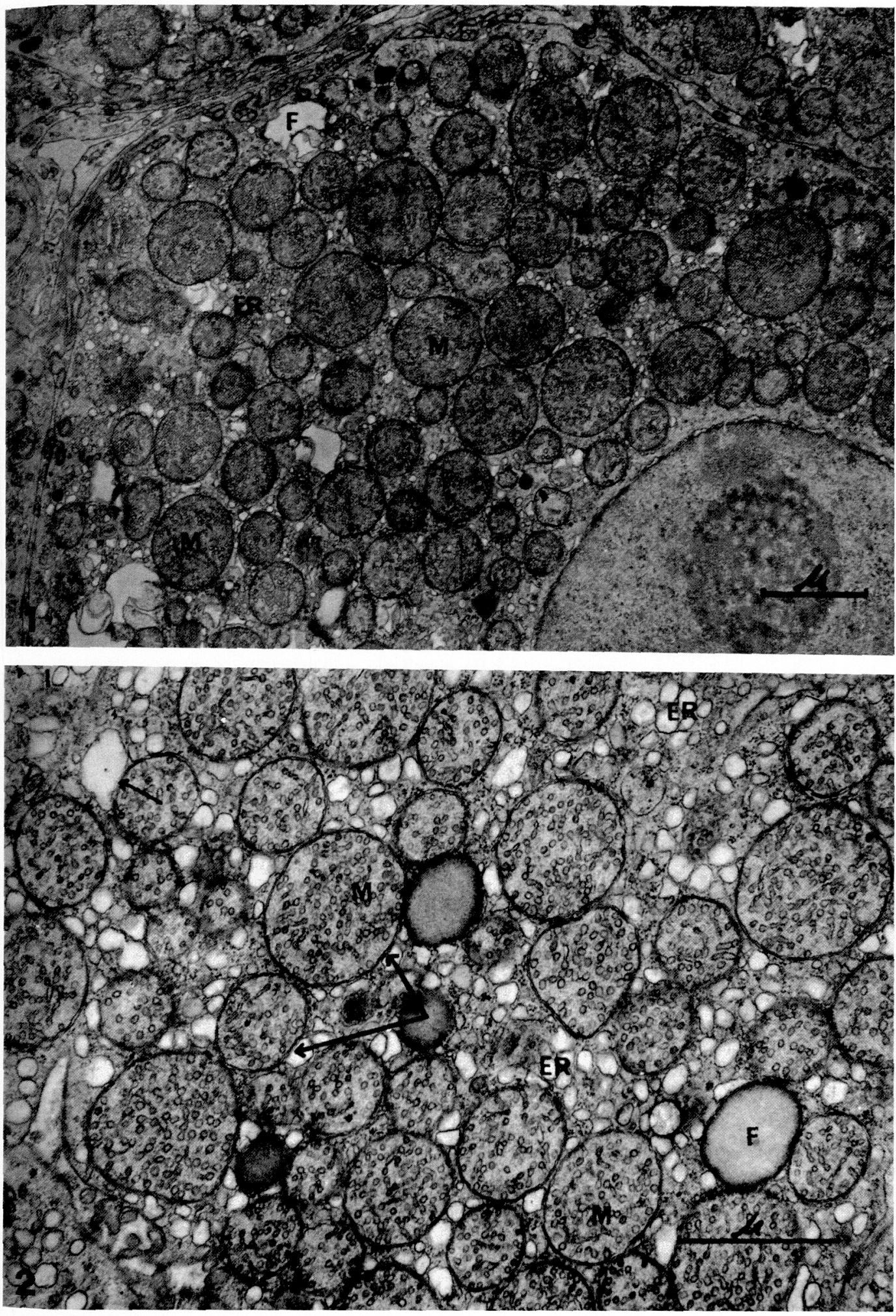
Fig. 3. Fasciculata cells from a male rat unilaterally adrenalectomized, 3 days after operation. In an acute phase, numerous expanded canalicular ER whose crosssections may be identical with the vesicles or vacuoles are intervened among the enlarged mitochondria (M) which often constitute a protuberance of the mitochondrial membrane (arrow). ER tend to adhere to the mitochondrial membrane. The plasmamembrane of the adjoining cells arrange in parallel, and a dilated space (double arrow) is sometimes interposed between the two membranes. DB, dense bodies. $\times 30,000$

Fig. 4. Fasciculata cells from a male rat unilaterally adrenalectomized 30 days after operation. The expanded ER following unilateral adrenalectomy reverted to the slender canaliculi in a chronic phase. The mitochondria are often surrounded by these canaliculi, which extend to approximate the free surface of the intercellular space equipped with the microvilli (MV). The canaliculi sometimes are found to open into the intercellular space (arrow). $\times 20,000$ 

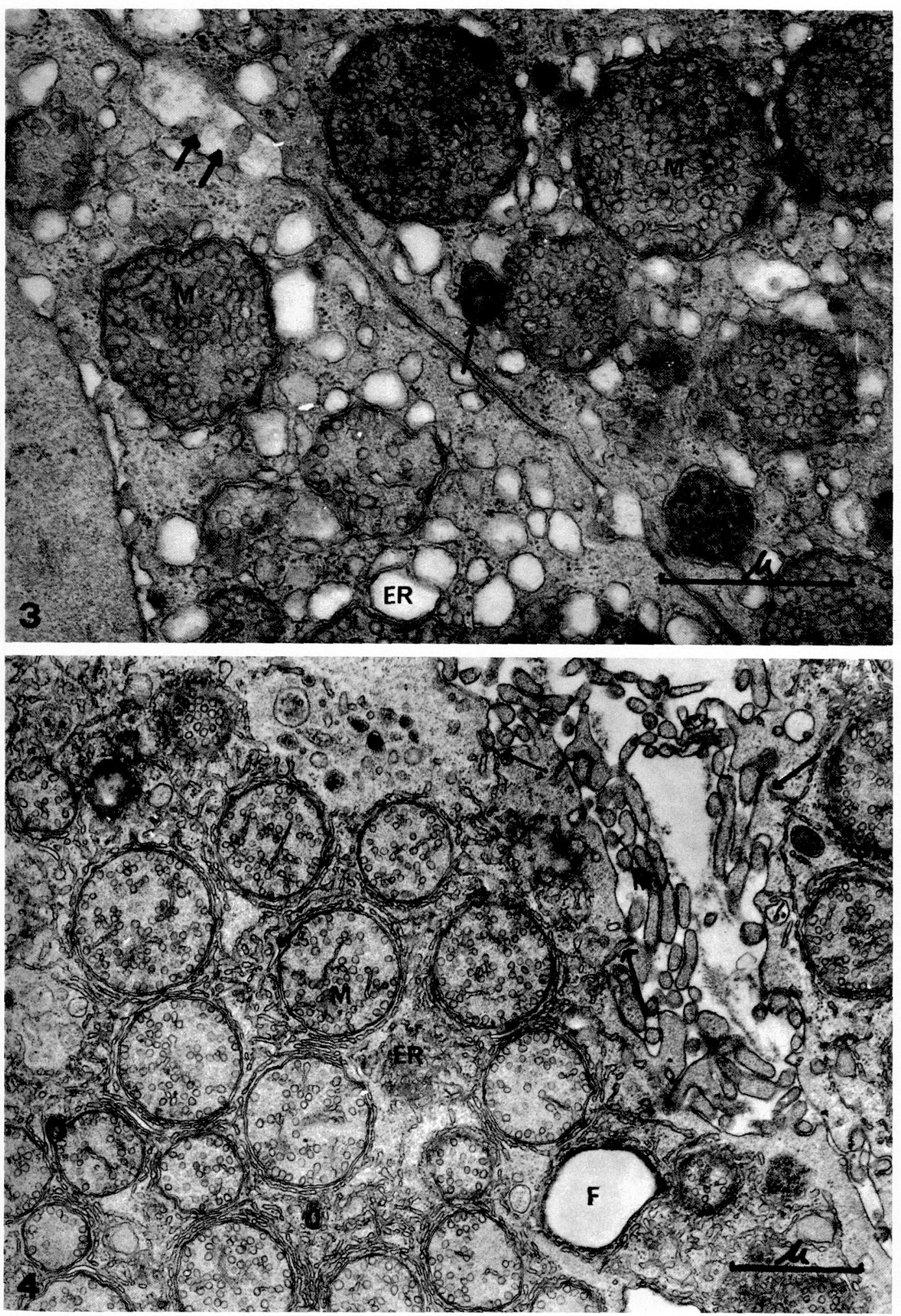
Fig. 5. Fasciculata cells from a rat, 30 mins. after the injection of snake toxin. Fat droplets (F) disappeared quickly. The hyaloplasm is poor in expanded vesicles, and a meshwork of the slender canalicular ER is present. $\times 18,000$

Fig. 6. Fasciculata cells from a rat unilaterally adrenalectomized, 1 day after operation. The acute subcellular change following unilateral adrenalectomy resembles a feature of the fasciculata cells in an acute phase of the rat stimulated by snake toxin. Compare Fig. 5 with Fig. $6 . \times 16,000$

Fig. 7. Fasciculata cells from a rat, 3 days after unilateral adrenalectomy was performed. The limiting membrane of vesicles is in contact with the external membrane of mitochondria (arrow). Close affinity of ER to the mitochondria is of great significance. $\times 40,000$

Fig. 8. Fasciculata cells of a rat, $6 \mathrm{hrs}$. after $200 \mathrm{mg} / \mathrm{kg}$ injection of snake toxin. The slender canaliculi are increased in number and in diameter, and the vesicle-like ER are congregated throughout the whole cell-body. Fat droplets remain in the cytoplasm even after $6 \mathrm{hrs}$. after $200 \mathrm{mg} / \mathrm{kg}$ injection of snake toxin. $\times 21,000$ 

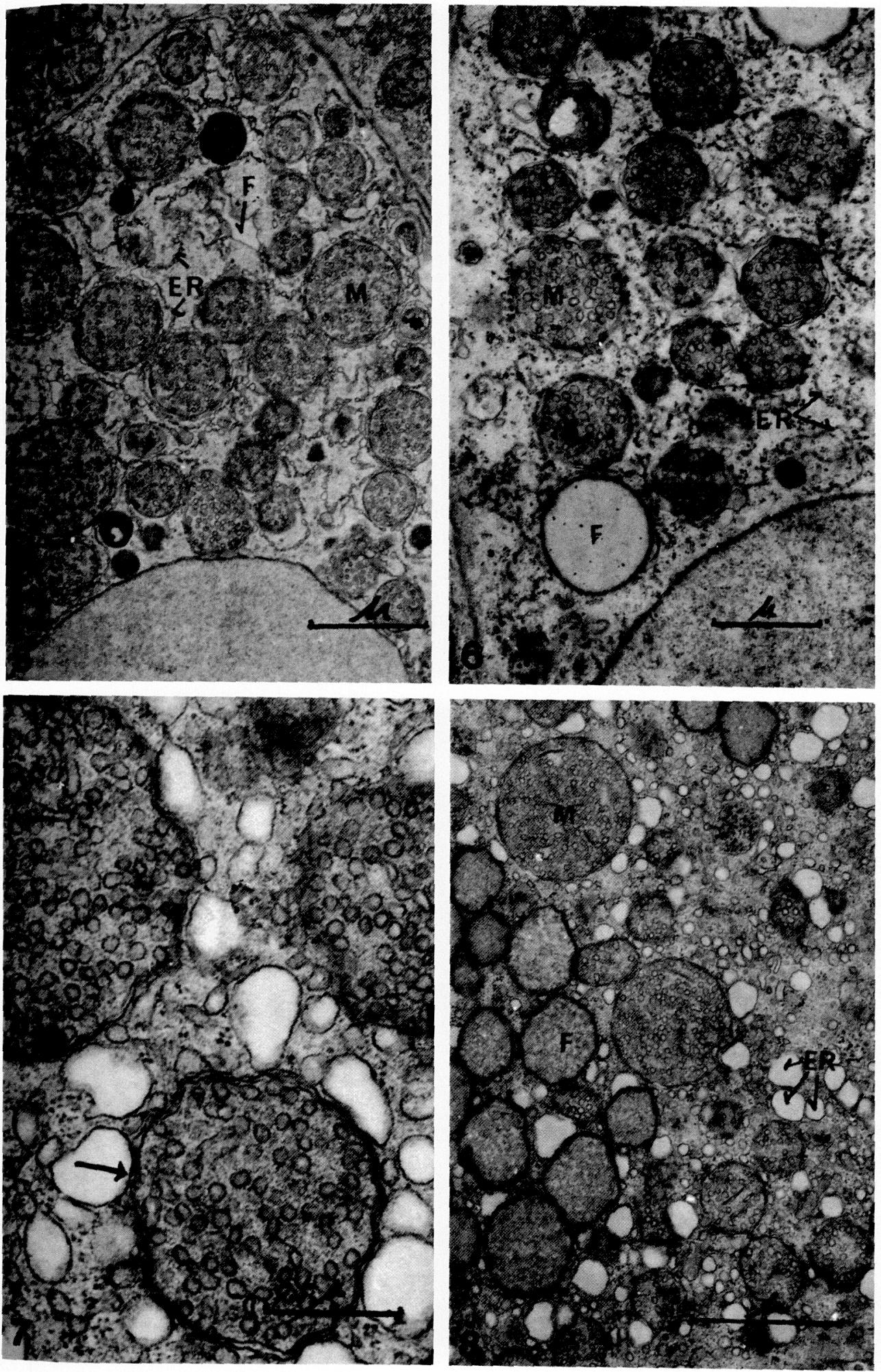
Fig. 9. A fasciculata cell from a hypophysectomized rat, 12 hrs. after hypophysectomy. The mitochondria are deformed into the irregular ones, elongated or crooked. The canalicular ER disperse, while the free ribosomes are unaffected. $\times 30,000$

Fig. 10. A fasciculata cell of a hypophysectomized rat, administered with $5 \mathrm{I}$. U. of ACTH after an interval of 12 hrs. Deformation of the mitochondria is improved, representing a normal picture. The network of canalicular ER becomes typical again in the cytoplasm. $\times 30,000$ 

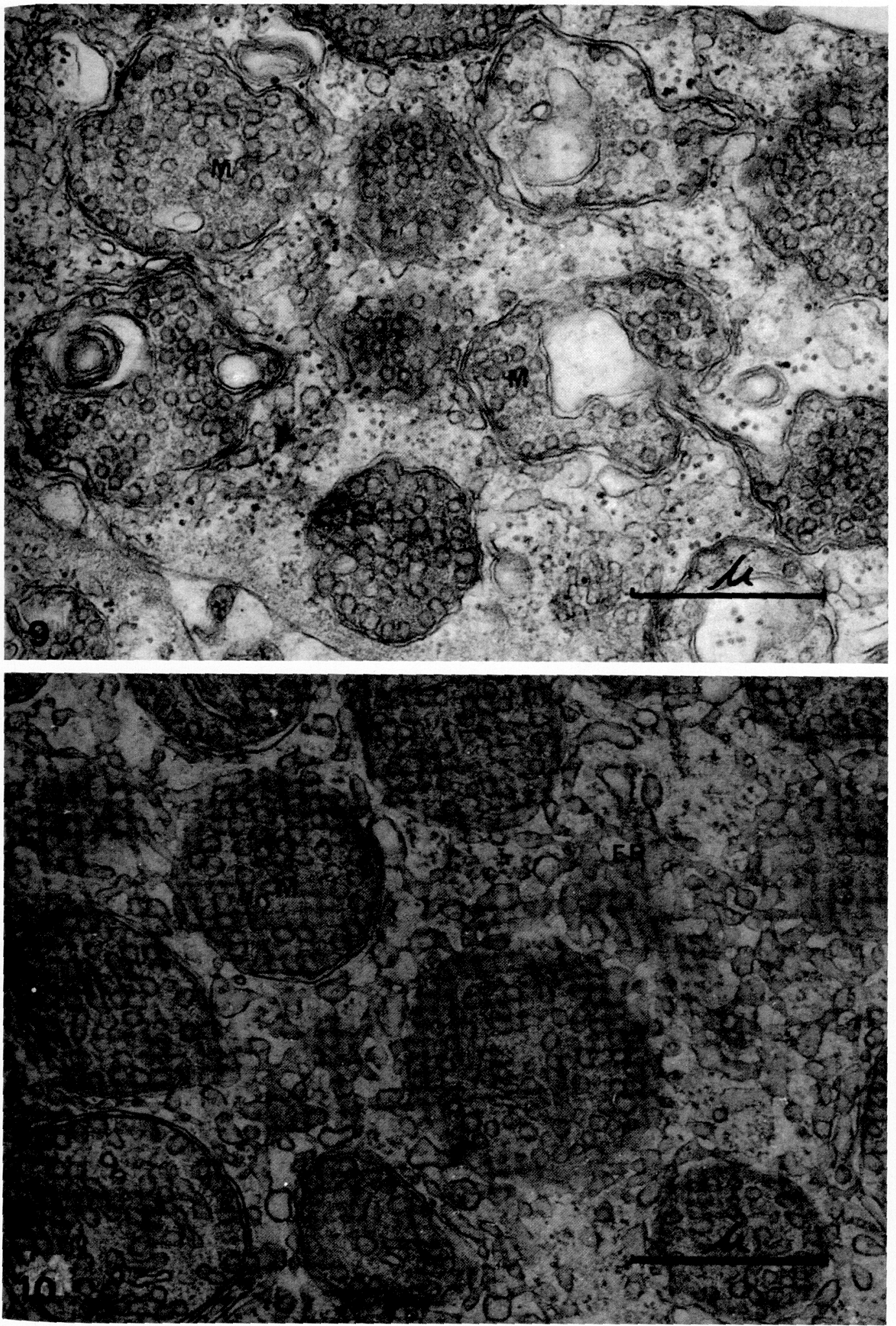
Fig. 11. Fasciculata cells from a hypophysectomized rat, 65 hrs. after operation. Degeneration becomes more serious with the lapse of time. Destruction of the mitochondria is progressive and the canalicular ER becomes atrophic. At left is seen a damaged cell: the hyaloplasm is poor in ER and has large or small inclusion dense bodies (IDB) in some places. The fat droplets (F) increase in number. $\times 20,000$

Fig. 12. Fasciculata cells from a hypophysectomized rat, administered with 5 I.U. of ACTH at an interval of $65 \mathrm{hrs}$. Note the mitochondria recovered from degeneration. Accumulated fat droplets are dispersed in the cells. The network of ER reappears. $\times 18,000$

Fig. 13. Fasciculata cells of a rat under the same condition. The anastomosing ER have been reproduced in the cells by ACTH administration. The canaliculi of ER enter the peripheral area of the cell surfacing the intercellular space. $\times 35,000$ 

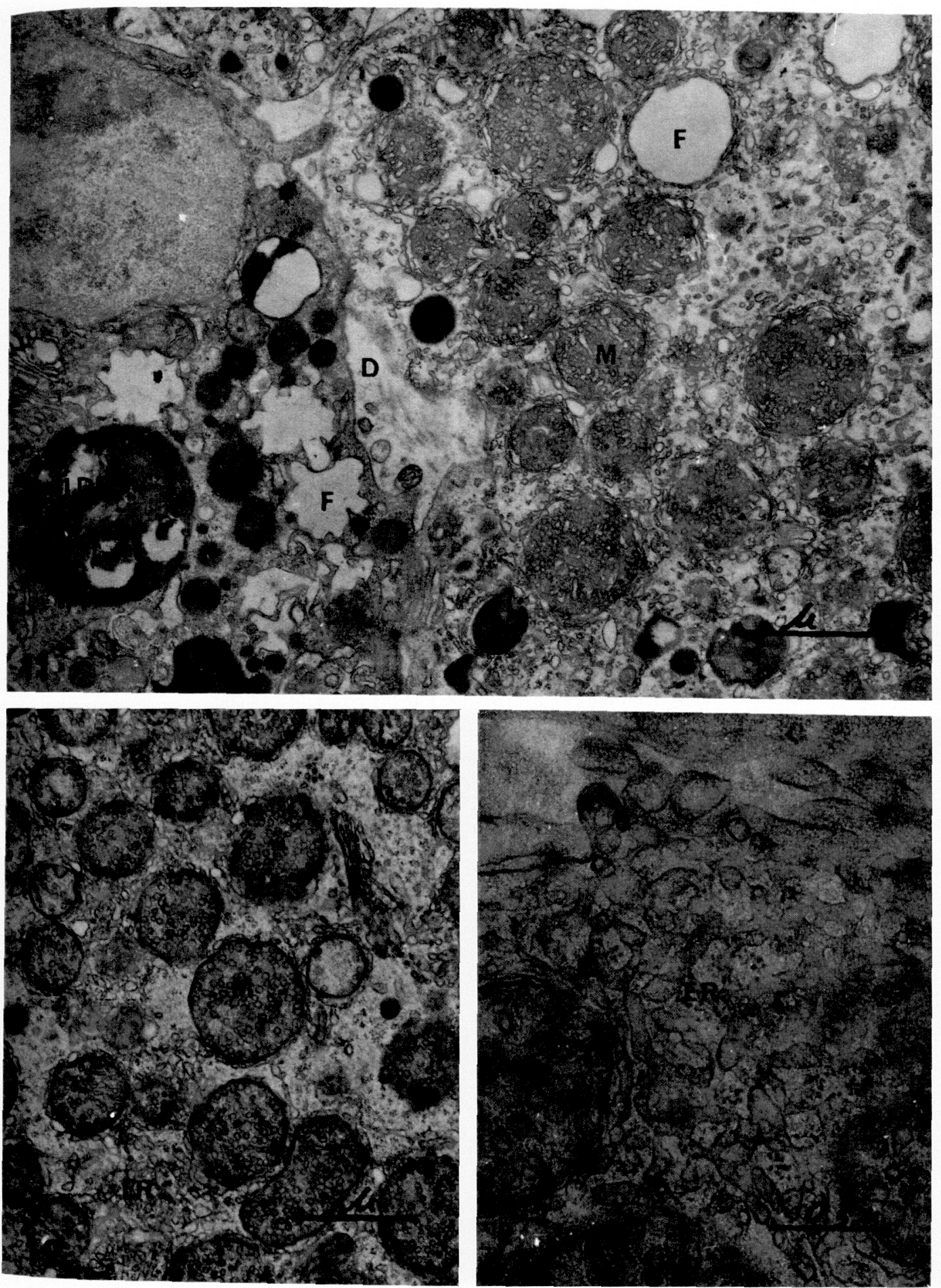
Fig. 14. Transitional (intermediary) cells of a hypophysectomized rat, 7 days after hypophysectomy. The transitional zone increases in width. These cells are characterized by an irregular shape of the mitochondria (M), loss of fat droplets and a large number of vesicles. At right is a fasciculata cell packed with fat droplets of irregular shape. $\times 13,000$

Fig. 15. Glomerulosa cells of the same hypophysectomized rat, seven days after operation. The deepermost cells of the zona glomerulosa have many fat droplets (F) and vesicles; the mitochondria $(\mathrm{M})$ are provided with the tubular cristae, which occasionally contain the parallel pseudocrystaline arrays. $\times 14,000$

Fig. 16. A fasciculata cell of a hypophysectomized rat, administered with 5 I.U. of ACTH after an interval of 7 days. The cell is no longer recovered from degeneration. Deformation of the mitochondria (M) and accumulation of the fat droplets are of a permanent nature. $\times 21,000$ 

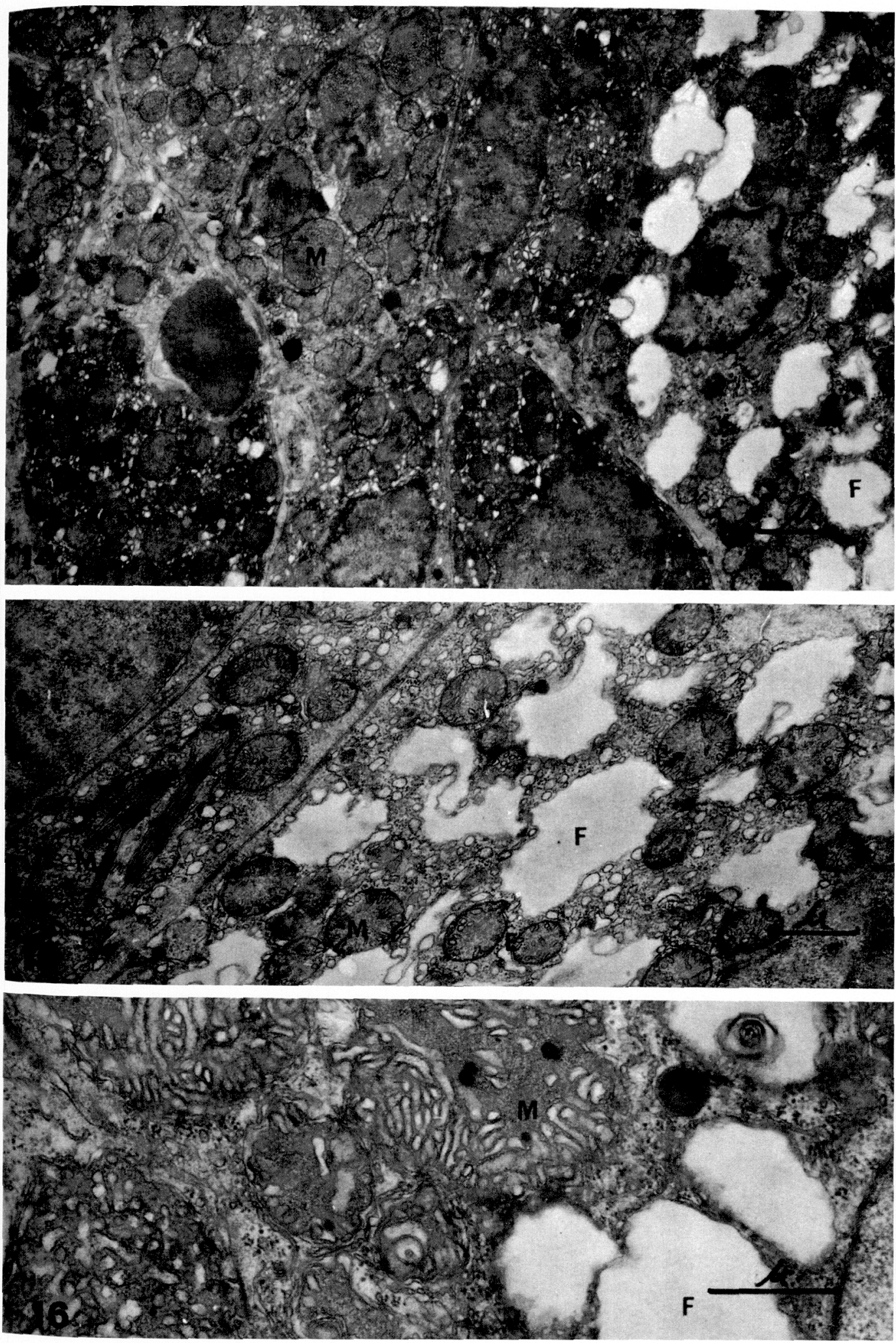
Fig. 17. Fasciculata cells from a hypophysectomized rat, 18 days after hypophysectomy. Deformation and destruction of the mitochondria (M) are most serious. Arrow shows the distribution of intramitochondrial vesicles at the peripheral edge, displaying a Japanese rattan blind fashion. $\times 15,000$

Fig. 18. Glomerulosa cells of the same hypophysectomized rat. These cells proliferate remarkably, and the boundaries between the adjoining cells are complicated. The mitochondria are unaffected, and the Golgi apparatus (G) is well developed. $\times 18,000$

Figs. 19 and 20. Fasciculata cells of a hypophysectomized rat, administered with 5 I.U. of ACTH after the interval of 65 hrs. Evidence is present that the canalicular ER open into the intercellular space (arrow). $\times 41,000, \times 30,000$ 

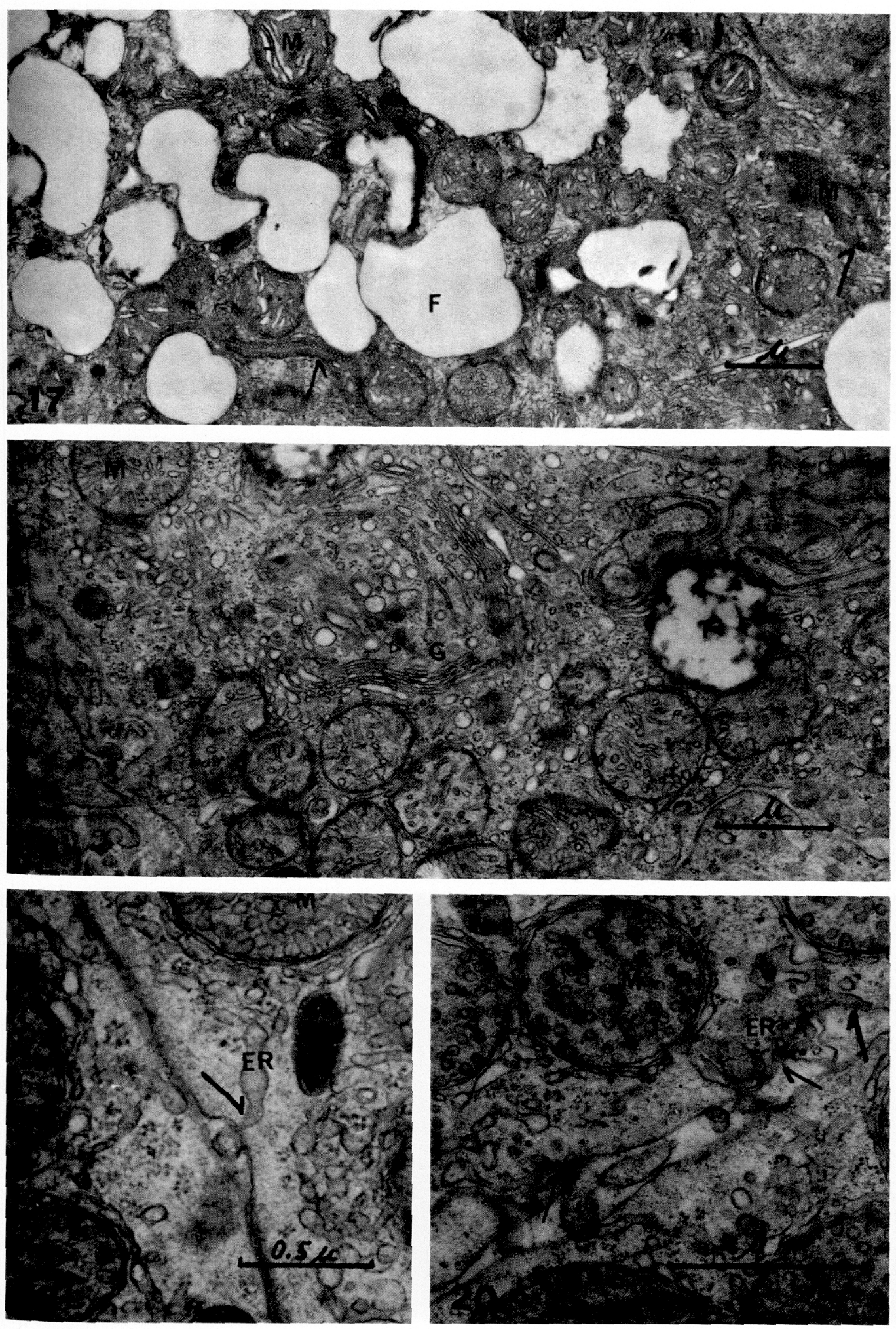